\title{
POR QUE PENSAR?
}

Coordenador: Leôncio Martins Rodrigues (Unicamp/Cedec)

Expositores: Boaventura de Sousa Santos (Universidade de Coimbra)

Gildo Marçal Brandão (USP)

Luiz Jorge Werneck Vianna (Iuperj) 



\title{
SEIS RAZÕES PARA PENSAR
}

\author{
BOAVENTURA DE SOUSA SANTOS
}

É um prazer enorme estar aqui, voltar aqui e fazê-lo nestas circunstâncias da celebração dos 25 anos do CEDEC, instituição que me habituei a respeitar há muitos anos, a admirar, a seguir e a colaborar na medida do possível, nos seus trabalhos e na sua revista, uma revista de resistência, de criatividade, de pensamento crítico sobre o Brasil. Por todas estas razões eu não poderia faltar à chamada que a Amélia fez e aqui estou, com todo gosto, pois.

Evidente que eu tenho aquele mínimo de decoro que se espera que um professor universitário tenha, de não pensar o Brasil no meio de colegas tão insignes, tão ilustres, que eu tanto admiro . Mas é evidente que a questão que me foi posta para esta ação é uma questão mais ampla sobre as razões para pensar sobre as sociedades contemporâneas. É uma questão realmente importante porque é desarmantemente simples. É fácil formular a pergunta, ainda que não seja fácil respondê-la. Costumo dizer que paradoxalmente é nos períodos de transição paradigmática que as perguntas simples fazem mais sentido. A complexidade destes períodos reside precisamente na nossa dificuldade em nomeá-los. E porque não sabemos nomeá-los falamos de períodos de transição. $\mathrm{O}$ curioso é que a complexidade, para ser desvelada, tem de ser interpelada de maneira simples. Acho que as questões simples são aquelas que, por serem desarmantemente transparentes, permitem ver melhor qual é a problemática dominante do nosso tempo.

O meu exemplo é sempre o de Rousseau, que em meados do século XVIII pôs aquela questão muito simples, muito importante na altura em que a ciência começava a ser o grande motor do desenvolvimento econômico, político e cultural: a questão de saber se a ciência e a virtude tinham alguma coisa em comum, se o desenvolvimento da ciência contribuiria para o bem da sociedade e para a melhoria dos costumes. Uma pergunta simples à qual ele respondeu com um redondo não, como sabem, depois de fazer, naturalmente, um discurso que aliás lhe granjeou um prêmio, nessa altura. 


\section{SITUAÇÃO COMPLEXA, PERGUNTAS SIMPLES}

Eu penso, realmente, que as perguntas que nós hoje precisamos são perguntas simples e esta é uma delas. Congratulo-me, portanto, com o fato de poder tentar dar-lhe a resposta. Naturalmente que não tenho a felicidade de ter a lucidez de Rousseau e poder responder com um redondo sim, ou não, ou com uma razão qualquer, que seja evidente e inequívoca para todos. Tenho que ir por aproximações sucessivas, ou seja, por respostas diferentes à mesma questão.

A primeira coisa que me intriga nessa pergunta é que ela parece estranha. Por que pensar? Afinal os cientistas sociais dos últimos dez anos têm vindo a dizer que nós estamos num período de auto-reflexividade, em que indivíduos autônomos refletem sobre os processos de transformação em que participam e usam essa reflexão para intervir nesses processos. $\mathrm{O}$ indivíduo auto-reflexivo é um indivíduo que não se mobiliza sem razões, a sua própria vida é um objeto de meditação, de reflexão, de auto-análise, de reversão de percursos etc.

Se nós estamos numa fase da auto-reflexividade, todos pensamos, e, se todos pensamos, por que fazer essa pergunta? A verdade é que, em minha opinião nós não estamos numa fase da auto-reflexividade. Ao contrário do que pensam Ulrich Beck, Scott Lash e Anthony Giddens, eu penso que nós não estamos numa época da auto-reflexividade, penso sim que estamos numa época em que a auto-reflexividade é própria daqueles que têm o privilégio de a atribuir aos outros. Ela não é, de modo nenhum, generalizada, e não é generalizada exatamente porque estamos num processo de transição, um processo de grande criação e de grande destruição. Não é a criação destrutiva ou a destruição criativa de que falava Schumpeter; são processos de criação, concomitantes com processos de destruição, sem que se saiba muito bem a coerência entre eles, muitas vezes. E nesse processo, penso eu, a vertigem das transformações faz com que a sociedade se divida em dois grupos que vivem em condições nada propícias a pensar. Por um lado, aqueles que comandam esse processo de criação e de destruição, aqueles que estão por detrás da globalização hegemônica de que hoje tanto se fala, aqueles que comandam todo esse processo, não têm tempo para pensar. Imaginemos que vamos perguntar a um stockbroker, a um corretor da bolsa, por que é que ele está a fazer o que está a fazer naquele momento. É evidente que fazer-lhe uma pergunta desse tipo é extremamente perturbador, porque obviamente o automatismo da sua ação não exige, não permite de maneira nenhuma esse pensamento. Por outro lado, enquanto ouviu a nossa pergunta 
e teve que lhe responder, perdeu certamente alguns investimentos chorudos, já que na bolsa não há tempo a perder. Por outro lado, aqueles que sofrem este processo de criação, a esmagadora maioria da população mundial, que neste momento sofre a exclusão, a desigualdade, a polarização entre ricos e pobres, tão pouco pode pensar, porque está tão ocupada em sobreviver que não tem, realmente, capacidade, nem tem disposição para pensar. Portanto, eu penso que no momento em que nós fazemos um apelo à auto-reflexividade, a sociedade vai destruindo as condições que a tornam possível de uma maneira generalizada. Isto, portanto, faz com que seja importante nós pensarmos, e pensarmos exatamente que a primeira resposta é exatamente essa: porque estamos numa fase de transição paradigmática, numa fase em que nós temos que pensar, realmente, qual é o tipo de conhecimento que nos pode levar a atravessar da melhor maneira esse processo de transição, porque as transições são processos em que há descontinuidades, há turbulências de escalas, há agitação, explosão mesmo de escalas, como eu costumo dizer, e o pensamento estabilizado em outras eras, em outros períodos, tem dificuldade em se adaptar a essa turbulência.

\section{UM OUTRO PENSAMENTO}

Portanto, nós precisamos de um outro pensamento, provavelmente de um outro conhecimento que nos conduza nesse processo, e esse conhecimento é um conhecimento que tem que ser produzido por outra forma. A própria universidade vai ser interpelada nas próximas décadas, ela que é a instituição da modernidade ocidental mais antiga, pelo menos a que mantém há mais tempo basicamente a mesma forma que tem hoje. É muito provável que ela tenha que sofrer modificações radicais nas próximas décadas, porque o processo de conhecimento a que hoje nós aspiramos não se compagina com muitas das formas institucionais em que é hoje praticado. E esse conhecimento, esse pensamento, tem que ter uma característica que me parece realmente complexa. É que ele tem que ser suficientemente igual ao seu tempo para poder imergir nele, para se poder afundar nele, para poder ser parte dele. Sabemos que nomeadamente o pensamento crítico moderno teve muitas vezes dificuldade nessa imersão, ressentiu sempre de alguma maneira a sua igualdade com o seu tempo, quis manter sempre uma diferença.

É necessário que o nosso pensamento seja simultaneamente igual a este tempo que é realmente complexo. Portanto ele tem que ter alguma turbulência, e algum caos, que é próprio do próprio tempo que ele quer pensar. 
Mas, ao mesmo tempo, tem que ser suficientemente diferente para poder pensar, para poder emergir, para poder ver com alguma distância crítica o que se está a passar. Portanto, o fato de estarmos num período de transição é, em meu entender, a primeira resposta a esta pergunta.

\section{A LUCIDEZ INDISPENSÁVEL}

A segunda resposta à pergunta por que pensar? pode formular-se da seguinte forma: porque a ação e a mobilização não dispensam a lucidez da ação e da mobilização. A ponta de verdade que a idéia da auto-reflexividade tem hoje não é detectável ao nível da auto-reflexidade individual, mas antes ao nível da auto-reflexividade coletiva, dos movimentos sociais, das organizações não-governamentais, onde, ao contrário de outros tempos em que mobilização, nomeadamente aquela que caracterizou o movimento operário, tomou a certa altura uma precedência total sobre a lucidez - como se a mobilização tivesse razões que a razão teria mesmo que desconhecer a reflexão sobre as razões da mobilização faz parte integrante da própria mobilização.

Estamos numa fase nova, onde a mobilização não dispensa a lucidez e onde, realmente, para as pessoas se mobilizarem para as lutas sociais têm que ter razões próprias. Portanto, eu penso que neste momento é fundamental que se tome nota de que neste período nós precisamos de um pensamento que permita essa mesma lucidez para ação e mobilização. E aqui, nesta resposta, a elaboração que vos faço e vos proponho é a seguinte: é que para isso ser feito é preciso que se criem constelações de sentido onde as tarefas intelectuais, as tarefas políticas e as tarefas morais de alguma maneira convirjam. E isto é, naturalmente, uma ruptura com o pensamento da modernidade.

A ruptura entre a busca da verdade e a busca do bem foi talvez o que de mais fatídico aconteceu à ciência moderna, porque a busca da verdade, separada da busca do bem, levou, efetivamente, ao reducionismo: o reducionismo como desconhecimento ativo da complexidade em nome do rigor da verdade. Esse desconhecimento ativo de complexidade transformouse numa verdade em si mesma: o rigor da verdade transformou-se na verdade do rigor, e a verdade do rigor acabou por boicotar o rigor da verdade.

Essa separação nem foi boa para a moral e a ética e nem foi boa para a ciência. Portanto, não é que nós não precisemos de rigor, o que não precisamos é da monocultura do rigor científico moderno. Precisamos de 
uma visão mais ampla de rigor. Por que? Precisamente porque nesta fase de transição é perigosíssimo dividir a busca da verdade da busca do bem. Entre parêntesis, notemos que a separação entre a busca da verdade e a busca do bem teve historicamente uma vantagem que é bom analisar e debater. Foi com base nela que os intelectuais, no fim do Ancien Regime, reivindicaram para si a tolerância dos poderes seculares e religiosos: como eram neutros podiam ser tolerados. Mas talvez por isso nós sejamos ainda semelhantes ao intelectual da Renascença, tal como o caracterizou um grande crítico literário cubano, Retamar: um misto de servo e de mercenário, lúcido para olhar a realidade, mas totalmente cooptado ou manietado nas possibilidades de a transformar.

Temos que reivindicar a tolerância, mas temos que a reivindicar por outra via. Porque são três as questões que se nos põem e elas têm que ser respondidas de modo articulado. Primeiro, onde estamos e para onde vamos é uma questão fundamentalmente intelectual, que podemos analisar com elementos cognitivos que temos, que a ciência e outros conhecimentos têm à nossa disposição. A segunda questão pode ser assim formulada: ante alternativas incertas, que é o que caracteriza um processo de transição, quais escolher? No fundo: de que lado estamos? Esta é uma questão moral, uma questão tão importante quanto a anterior. E finalmente há uma terceira questão: uma vez definidas as prioridades ou as alternativas pelas quais nós nos queremos pautar a nossa existência, como chegar lá? É a questão política. Portanto, há questões intelectuais, morais e políticas que se misturam.

\section{POR UMA NOVA CIÊNCIA SOCIAL}

Para que possamos criar novas constelações de sentido que nos permitam responder articuladamente as três questões nós precisamos, realmente, de outras ciências sociais e de um outro tipo de cientista social.

Em primeiro lugar eu penso que é fundamental, como tenho defendido, que distingamos entre objetividade e neutralidade. A objetividade é fundamental, a neutralidade deve ser superada. A idéia da objetividade, normalmente, conota três idéias distintas: a imparcialidade, que tem muito a ver com o fundamento das teorias; a neutralidade que é indiferença às consequiências da teoria; e a autonomia, que diz respeito à independência das práticas e das instituições científicas. Da imparcialidade não me ocupo neste momento. A autonomia é hoje um dos grandes problemas da ciência. A neutralidade ou indiferença às conseqüências é que eu penso que tem que ser 
superada, isto é, nós temos realmente de ser capazes de sermos objetivos sem sermos neutros.

Sermos objetivos significa analisarmos a realidade com as técnicas e os métodos que estão à nossa disposição, sem sectarismos nem dogmatismos. Perguntarão: mas como é que podemos evitar o sectarismo ou o dogmatismo se não formos neutros? Respondo: através de um procedimento muito importante, extremamente exigente mas também simples que consiste em estarmos sempre preparados para nos deixarmos surpreender pela realidade. Enquanto a gente se deixar surpreender pela realidade, no sentido de que aquilo que nós observamos não está totalmente contido nas nossas teorias, ou nos nossos preconceitos, aí estará prevenido o perigo do sectarismo. Portanto, o importante é que saibamos que o compromisso com a objetividade existe para fundar a objetividade do compromisso, isto é, para termos razões pelas quais nós temos uma posição ou outra. O cientista social, sendo objetivo, tem que saber de que lado está e tem que saber com razões, razões pensadas, e é por isso que é preciso e é fundamental pensar. Não há objetividade sem objetivos.

Em segundo lugar, temos que substituir o conhecimento heróico pelo conhecimento edificante, um conhecimento que não é estranho às consequiências do conhecimento. $\mathrm{O}$ conhecimento científico cometeu muitos epistemicídios, produziu muita morte de conhecimentos alternativos. Precisamos de denunciar esse epistemicídio e de recuperar na medida do possível os conhecimentos alternativos. Ao contrário do que proclamam os arautos da globalização o mundo é cada vez mais diverso e nessa diversidade emergem novas formas de conhecimento. Por outro lado, a ciência, ela própria é multicultural.

O novo cientista social tem que ser o contrário do ideólogo. Quem é o ideólogo? É aquele que gera a ocultação das discrepâncias entre os objetivos generosos e as práticas egoístas e corruptas. O intelectual, o cientista social, tem que ser o contrário disso, tem que ser duas coisas neste momento: tem que ser, por um lado, tradutor e tem que ser, por outro lado, a voz. Tradutor no sentido que tem que contribuir para ampliar a inteligibilidade das práticas sociais e das mobilizações sociais.

As práticas sociais hoje são simultaneamente globais e locais. É preciso amplificar a inteligibilidade entre as diferentes práticas, entre o movimento indígena e o movimento das mulheres, entre o movimento negro e o movimento pacifista, entre o movimento ambiental, entre movimentos regionais, entre os movimentos de moradores e os movimentos homossexuais. O cientista social tem um papel crucial de, através da sua prática e do 
seu treino, não criar grandes teorias, mas permitir aumentar a inteligibilidade entre as diferenças: o que o movimento indígena tem a ver com o movimento ambiental, o que o movimento ambiental tem a ver com o movimento homossexual, ou com o movimento das mulheres. É esta inteligibilidade ampla que nós precisamos, porque estamos exatamente num processo em que o fechamento disciplinar fecha a inteligibilidade.

Por outro lado tem que ser a voz, a voz ante os silenciamentos, que o nosso sistema social/político/econômico cria. Uma das grandes tarefas nossas é aquilo que eu chamo de "Sociologia das ausências", é procurar o que falta no presente, naquilo que existe. A negatividade do presente não é o que lhe falta, é o que no presente bloqueia aquilo que nos faz falta e a que temos direito É essa falta, essa negatividade que é fundamental para a nova forma de pensamento que vos proponho. Aí há uma distância, digamos, há uma distância que se mede por uma certa negatividade. Vivemos em sociedades ideologicamente afirmativas. A sociedade de consumo é por excelência uma sociedade afirmativa: depois de sujeitar os gostos ao menu de escolhas que oferece, naturalmente tem um menu para todos os gostos. No desarmar essa armadilha reside a negatividade do pensamento crítico neste momento. Nisto consiste a segunda resposta à nossa pergunta.

\section{PENSAR ALTERNATIVAS}

A terceira resposta à pergunta por que pensar? é a seguinte: porque é preciso lutar contra o des-pensamento que está por detrás da despolitização da transformação social, ou seja, a idéia de que não há alternativas à globalização hegemônica. Precisamos de pensar para podermos credibilizar as alternativas que estão a emergir no mundo. E para isso nós não precisamos apenas de um pensamento de alternativas, precisamos de um pensamento alternativo de alternativas. $\mathrm{O}$ pensamento alternativo caracteriza-se pela centralidade da hermenêutica da emergência: para credibilizar as alternativas que estão a emergir no mundo precisamos de uma hermenêutica de emergência, que amplie simbólica e politicamente essas iniciativas locais.

Há duas grandes idéias a ter em conta. A primeira é de Prigogine (e de Aristóteles), a idéia de que o possível é mais rico que o real. A segunda é uma idéia de Ernst Bloch, um filósofo que não é hoje muito lido, mas que devia sê-lo muito mais: o conceito do "ainda não", entre o ser e o nada, que funda o princípio da esperança! Nós vivemos em sociedades onde há espera mas onde não há esperança, e para reconstituir essa esperança, o 
princípio do "ainda não", de algo que pode vir, que é possível, porque está nas possibilidades do real e do presente, cria um efeito de intensificação. $\mathrm{O}$ ainda não tem uma energia superior à sua matéria precisamente por não estar ainda realizado. É ele que nos evita, realmente, a aceitação do que existe só porque existe, nas suas três formas: o conformismo, que é a maneira chã, mais plana, de aceitar o que existe; o situacionismo, que é a celebração total do que existe; e o cinismo, que é o conformismo com má consciência.

Este "ainda não" exige um elemento subjetivo, e esse elemento subjetivo é a consciência antecipatória, a idéia de que algo pode surgir, em que a ruptura entre o presente e o passado é possível, a latência do futuro, a idéia de incompletude. E, de novo, a idéia da sociologia das ausências é aqui muito importante, porque ela nos leva a mostrar que o que existe está aquém do que pode existir, que há possibilidades irrealizadas e que são realizáveis, são as chamadas utopias reais. Precisamos de surpresas que tenham condição para não ser, ou seja, surpresas realistas.

Esta hermenêutica da emergência obriga realmente a ciência a confrontar-se com conhecimentos rivais, e é essa uma das deficiências da universidade e dos nossos próprios centros de investigação: não sabemos trazer para dentro deles outros conhecimentos, a não ser em momentos muito raros. Lembro-me de, em 1974, quando foi a revolução dos cravos em Portugal, trazermos camponeses das cooperativas a darem aulas conosco sobre cooperativismo. Tão pouco sabiam eles de cooperativismo quanto nós mas sabiam melhor que nós porque era importante criar cooperativas. Era uma outra configuração de sentidos cognitivos, políticos e morais, uma outra possibilidade de colaboração, que depois se desvaneceu à medida que nós voltamos a ser universitários e intelectuais e eles, obviamente, camponeses como sempre tinham sido.

\section{PENSAR NÃO É TUDO}

Quarta resposta à pergunta por que pensar? Porque pensar não é tudo, porque além de agir nós temos que sentir, nós temos que criar formas de pensamento que sejam mais acolhedoras às emoções, ao corpo, aos afetos, ao sentimentos. Isso também é uma grande dificuldade para o conhecimento em que fomos treinados. As ações coletivas de transformação social têm essa dupla característica de resistência e de criatividade e quer uma quer outra exige envolvimento emocional, entusiasmo e indignação. O próprio ódio é por vezes necessário, ao mesmo tempo que o amor, e a solidariedade, 
ou seja, elementos de sensibilidade com os quais a modernidade ocidental sempre se achou muito mal.

Proponho para reflexão, que nós somos feitos de duas correntes, a corrente fria e a corrente quente. A corrente fria é a corrente do conhecimento dos obstáculos, das condições da transformação. A corrente quente são as possibilidades da vontade, de agir, de transformar, de vencer os obstáculos. A corrente fria impede-nos de sermos enganados; conhecendo as condições nós não somos enganados. A corrente quente impede-nos de nos desiludirmos facilmente; a vontade do desafio sustenta o desafio da vontade.

Mas como tudo, o que é bom tem sempre a sua perversão. $O$ medo exagerado a sermos enganados tem um grande risco: transforma as condições em obstáculos incontornáveis e, ao fazê-lo, conduz ao quietismo e este, ao conformismo. $\mathrm{O}$ medo exagerado de não nos desiludirmos cria uma aversão total a tudo o que não se apalpa, não se vê imediatamente. Por esta via conduz à aversão à mudança e esta, igualmente, ao conformismo.

Neste contexto é preciso refletir sobre o papel da arte, porque a arte é a pré-aparição das possibilidades utópicas, a arte é o laboratório e a festa dessas possibilidades. Curiosamente a modernidade ocidental valorizou-a, pondo a um canto, o chamado horror pulcri dos modernos. A arte exprime de maneira exemplar as possibilidades contidas no real.

\section{LUCIDEZ E AUTONOMIA}

Quinta resposta à pergunta por que pensar? Porque as lutas lúcidas não conduzem, necessariamente, a resultados lúcidos. É muito importante ter sempre presente que as nossas lutas, por mais lúcidas que sejam, podem ter resultados perversos. A ciência moderna é um bom exemplo desse risco porque a ciência moderna desenvolveu uma enorme capacidade de ação mas uma péssima capacidade de previsão das suas consequiências. É por isso que as consequiências de uma ação científica são sempre menos científicas do que a ação em si mesma.

Ora bem, é muito importante que a gente saiba que as nossas lutas, os nossos movimentos levam, por vezes, a resultados perversos. Neste momento de complexidade nós precisamos de capacidade de ação, que por um lado tenha determinação sem fechamento, tenha intenção mas seja capaz de progredir no caos, tenha horizontes mas não tenha metas, tenha critérios mas não tenha programas, tenha direitos mas esteja aberta à ilegalidade. Aqui se funda a passagem da ação conformista à ação rebelde de novo tipo: a ação 
rebelde que exige, tanto razões para ser empreendida, como razões para os perigos da sua perversão.

Sexta resposta à pergunta por que pensar? Porque não podemos confiar em quem pensa por nós, em quem se arroga a pensar por nós. Por que? Porque nos dizem uma série de coisas que é perigoso tomar por verdadeiras.

Primeiro, já vimos que nos dizem que não há alternativas, que a globalização hegemônica é esta e não há outra. Nós sabemos que há alternativas, como demonstrou eloqüentemente o primeiro Fórum Social Mundial de Porto Alegre: Davos de um lado e Porto Alegre do outro, e alegra-me muito que o nome da alternativa, metaforicamente, seja agora um nome brasileiro.

Em segundo lugar, dizem-nos que a compatibilidade entre a democracia e capitalismo é a grande conquista da globalização. A tensão entre democracia e capitalismo existiu sempre na modernidade ocidental, e existiu por uma razão simples, é que o processo de inclusão deu-se sempre por via da redistribuição social. A democracia foi o processo hegemônico de realizar redistribuição através das sucessivas ampliações dos direitos de cidadania. As transferências de rendimento exigidas pelo aprofundamento da cidadania tinham de criar, por força, tensões com o capitalismo, sempre avesso à redistribuição. Se hoje as tensões parecem ter desaparecido é porque a democracia está a deixar de ser redistributiva. As crises na saúde, na educação, na seguridade social são as crises da redistribuição.

Em terceiro lugar, dizem-nos que são baixos os níveis de contestação social porque as transformações são consensuais. É nossa obrigação distinguir entre consenso e resignação. Há hoje muito menos consenso do que resignação. A distinção entre eles é fundamental. O consenso é a afirmação do conflito resolvido, a resignação é a negação do conflito, e, por isso, sustentam duas estratégias de dominação muito diferentes. A própria teoria crítica não está preparada para lutar num mundo onde não é o consenso que domina, mas é resignação. A teoria crítica foi constituída contra o consenso e não sabe como defrontar a resignação.

Em quarto lugar, dizem-nos que o princípio de igualdade é inatingível, porque a riqueza cria a polarização e que, de qualquer maneira, o princípio da igualdade e o princípio da diferença são incompatíveis. Dizem até que a luta pelo multiculturalismo e pela diversidade é o prêmio de consolação para quem perdeu a luta pela igualdade. É preciso afirmar que nas novas lutas se procura o equilíbrio forte, tenso, dinâmico, entre o princípio da igualdade, o princípio da liberdade e o princípio da diferença, e que ape- 
sar de vivermos em sociedades muito desiguais, a igualdade não nos basta, queremos ser iguais e queremos ser diferentes.

Em quinto lugar, dizem-nos que o Estado é o contrário da sociedade e não é o espelho da sociedade. Portanto, a sociedade, para ser forte, tem que ter um Estado fraco. Ao contrário, temos que mostrar que uma sociedade civil forte exige um Estado social forte.

Dizem-nos finalmente que a descoincidência entre o indivíduo e a sociedade - que foi uma conquista da modernidade ocidental, e que está formulada em três grandes pensadores desse período, Marx, Nietzsche e Freud - não existe mais, porque o que há afinal são apenas os indivíduos. É importante mostrar que não é o indivíduo que está a emergir, é o individualismo como ideologia dominante do coletivismo situacionista.

Termino. Penso que esta pergunta nos põe uma exigência internamente contraditória: temos que pensar, mesmo que a experiência do pensamento não coincida com a experiência da vida. Temos dois exemplos, no século XX que são notáveis a esse respeito, Kafka e Pessoa. Com vidas tão monótonas, com vidas tão medíocres, como foi possível pensar tanto! Temos que nos preparar, realmente, para que haja descoincidências entre o pensar e o agir. E pensar que é precisamente por isso que é tão importante pensar o agir, como pensar o pensar. Pensar nestas condições desafiantes implica uma transformação da subjetividade: é que só se pode produzir o mundo se nós o pensarmos produtivamente e não consumisticamente. $\mathrm{O}$ que significa que a capacidade de fazermos coisas diferentes pressupõe a nossa capacidade de sermos pessoas diferentes. 



\section{IDÉIAS E INTELECTUAIS: MODOS DE USAR}

GILDO MARÇAL BRANDÃO

Hesitei diante do porte da tarefa quando Amélia me convidou para tomar parte nesse evento em torno do aniversário do CEDEC. Pois não se trata de um aniversariante qualquer. Com efeito, em um país onde as instituições costumam durar o tempo de interesse de seus fundadores, quantas podem comemorar 25 anos? Em um país que tem sido submetido a mudanças aceleradas em concentrado período de tempo, quantas instituições universitárias deixaram marca no debate público? Em um país no qual a vida acadêmica tem se confrontado com tanta burocracia e risco de taylorização, quantas instituições de pesquisa conseguiram renovar o seu projeto? Em um país em que as transformações ideológicas e as trocas de lado político foram tão intensas e conflituosas, quantas instituições intelectuais foram capazes de reafirmar seu compromisso de nascença com a esquerda, e de rejuvenescê-lo?

Não é preciso concordar com a problemática, tônica e evolução políticas do CEDEC para constatar o quanto ele se tornou parte integrante da história intelectual de uma geração. Não é esse, é claro, o momento de escrevê-la. Basta lembrar que é possível reconhecer em uma série de temas, problemas, formas de abordagem e argumentos que se disseminaram nas ciências sociais brasileira e latino-americana desses anos, a marca intelectual e política de quem as patrocinou. Assim, esse centro de estudos e debates sobre a cultura contemporânea nasceu trazendo à tona a crítica ao sindicalismo e à esquerda então existente, identificando a contradição básica do experimento do após-guerra no amálgama entre uma estrutura sindical estatalizada e corporativa com uma democracia representativa de participação ampliada, reivindicando a autonomia do estado vis-à-vis as classes sociais, alçando o conceito de populismo à condição de matriz explicativa da conturbada política latino-americana, recusando um modo de fazer política estruturado em torno de grandes alianças e repropondo os temas da autonomia do sindi- 
cato e da organização da sociedade civil em contraposição aos protagonismos do Estado e mesmo do partido político.

No momento da crise dos grandes paradigmas - como se costuma dizer - foi pioneiro na revalorização da dimensão simbólica da política, na justificação intelectual dos novos movimentos sociais e na postulação da existência de novos e plurais sujeitos sociais, que responderiam à experiência de fragmentação do mundo e à consciência do esgotamento do "modelo" da classe-sujeito responsável tanto pela mudança da realidade como pelo seu conhecimento. Também aqui, a questão da autonomia da sociedade civil diante de uma concepção da política centrada no estado e nas alianças políticas continuava em primeiro plano.

Se minha periodização não é simplificadora, diria que a radicalização da crise na virada dos anos 90 provocou uma reação de autodefesa e distanciamento da práxis anterior, logo traduzida no esforço de incorporação dos problemas e das formas de abordagem da ciência política institucionalizada e pela reflexão crítica sobre a situação e as políticas sociais implementadas pela nova democracia. $\mathrm{O}$ acento aqui se deslocou da "política instituinte" - um termo originário da filosofia política francesa e que denotava o horror à positividade - para os processos de construção institucional em que o país e a América Latina mergulhavam. Mas mesmo nessa fase, permaneceu a ponta de desconfiança tanto diante do Estado como em relação a uma perspectiva estritamente maquiaveliana da política, como se o CEDEC, reconhecendo malgré tout a centralidade da ética da responsabilidade, insistisse sempre no elemento de convicção, com receio de que o cálculo racional das conseqüências da ação derivasse em mero instrumentalismo e que o compromisso do ator com o caminho escolhido se reduzisse à mera accountability. O melhor produto dessa delicada redefinição tem sido, a meu juízo, a revista Lua Nova, que, do número 15 de outubro de 1988 em diante, não só acompanhou analiticamente a transição à democracia, como se tornou o principal pólo da nacionalização do debate norte-americano e europeu em torno da teoria política democrática, especialmente aquela normativa, ao tempo em que se abria à revitalização das pesquisas sobre o pensamento político brasileiro, complementaridade que garantiu à publicação notável individualidade no mundo cultural.

Ninguém terá dificuldade em situar essas mudanças intelectuais em seus contextos sócio-políticos nacional e mundial. Agora, pela palavra de Amélia, o CEDEC faz uma reafirmação de sua identidade de esquerda. E o faz conectando-a diretamente à questão de "por quê" e "como" pensar o Brasil — como se uma não fosse sem a outra. Eis o segundo motivo de meu 
temor. Porque a pauta não é exclusiva da instituição nem é reproposta em um momento qualquer. A mera necessidade de pôr a pergunta revela o quanto ela obriga a tomar distância do bravo novo mundo que a história nos legou, o quanto a nossa é uma consciência infeliz. Sequer temos certeza clara e distinta da relevância de nossa experiência e é impossível fechar os olhos à heteronomia de nossa condição social e espiritual; frequientemente deploramos a insuficiência das matrizes e categorias intelectuais com que as abordamos. Por outro lado, sabemos que numa conjunção crítica como essa, o país que devemos construir nem sempre é o que pode ser construído e, de qualquer maneira, tal construção depende estreitamente de como interpretamos sua trajetória histórica e suas possibilidades objetivas. A própria conexão reivindicada indica que a identidade retomada não pode ser fundamentalista, seja porque o caráter ideológico aparentemente adverso da era atual tem pelo menos a vantagem de nos constranger à ousadia intelectual, seja porque a sua consistência está hipotecada à qualidade e à amplitude das respostas que formos capazes de dar ao mundo fora de nós.

\section{NINGUÉM PENSARÁ POR NÓS}

Entro no meu tema, portanto, reconhecendo a complexidade da questão e acossado pelo desafio que ela representa. De fato, quando imaginava qual poderia ser um comentário consistente a "por que pensar o Brasil?", o primeiro argumento que me veio à mente foi: porque se não o fizermos ninguém o fará. Cada um de vocês reconhecerá aqui, transposto para o pensamento social e político brasileiro, a observação de Antônio Candido no prefácio à 1a. edição de Formação da Literatura Brasileira quando tentava justificar a - e se justificar pela - ocupação com esse gênero considerado menor:

Há literaturas de que um homem não precisa sair para receber cultura e enriquecer a sensibilidade; outras, que só podem ocupar uma parte de sua vida de leitor, sob pena de lhe restringirem irremediavelmente o horizonte. Assim, podemos imaginar um francês, um italiano, um inglês, um alemão, mesmo um russo e um espanhol, que só conheçam os autores de sua terra e, não obstante, encontrem neles o suficiente para elaborar a visão das coisas, experimentando as mais altas emoções literárias.

(...) A nossa literatura é galho secundária da portuguesa, por sua vez arbusto de segunda ordem no Jardim das Musas... (...) Comparada 
às grandes, a nossa literatura é pobre e fraca. Mas é ela, não outra, que nos exprime. Se não for amada, não revelará a sua mensagem; e se não a amarmos, ninguém o fará por nós. Se não lermos as obras que a compõem, ninguém as tomará do esquecimento, descaso ou incompreensão. Ninguém, além de nós, poderá dar vida a essas tentativas muitas vezes débeis, outras vezes fortes, sempre tocantes, em que os homens do passado, no fundo de uma terra inculta, em meio a uma aclimação penosa da cultura européia, procuravam estilizar para nós, seus descendentes, os sentimentos que experimentavam, as observações que faziam - das quais se formaram os nossos.

O que vale para a literatura vale, a fortiori, para o pensamento político, gêneros intelectuais que, salvo engano, têm sido as formas privilegiadas de se haver com a intratabilidade de nossa experiência. Ainda que a grande literatura haja lidado com esta de maneira mais ampla, aquele também produziu os seus Machado de Assis, Graciliano Ramos e Guimarães Rosa. Quer isto dizer que se o lugar de onde se fala não é neutro, não há entretanto porque alimentar qualquer sentimento de inferioridade ou exibir traço de mentalidade colonizada - também no caso do pensamento político abre-se a possibilidade de que a fraqueza se converta em força, o atraso em vantagem. Dado que a aventura espiritual de que estamos falando não é a da singularidade auto-referente nem deve ser a do cosmopolitismo abstrato esse hoje cada vez mais hegemônico -, mas sim a "do espírito do Ocidente, procurando uma nova morada nesta parte do mundo" (a formulação ainda é de Antônio Candido), o inverso também pode ser verdadeiro: a análise da parte pode iluminar, de ângulo inusitado, a natureza e a evolução do todo, a crítica da parte pode vir a ser a crítica do todo, vale dizer, da cultura, do capitalismo e da política mundiais. Dito de outro modo, na medida em que não se pode pensar a nação nos limites da nação, não é possível pensar o Brasil sem situá-lo no mundo. Mas a maneira de fazê-lo torna possível - ou não pensar o próprio mundo da perspectiva do Brasil.

Ninguém, entretanto, o fará por nós e, por isso mesmo - este é o meu segundo argumento -, estamos condenados a fazê-lo. De fato, se o papel das idéias políticas não é demiúrgico, mas também não é ou deixou de ser ornamental, é porque o próprio processo só se constitui como tal quando um pensamento sobre ele se articula, em disputa de morte contra formulações alternativas, para ser reconhecido como a sua expressão. Para o bem e para o mal, a relação entre processo e projetos não é apenas histórica, mas estrutural: boa parte do conflito político em países de capitalismo retardatário, 
democracia frágil e globalização subalterna como o nosso, continua a girar em torno de interpretações, do modo como os sujeitos que contam, especialmente em conjunções críticas, pensam o país e, em função disso e dos interesses que abraçam, lutam para lhe imprimir direção. Para usar uma linguagem em desuso, a experiência social é tal ordem que constelações como aquelas são parte não desprezível do universo pelo qual os homens tomam consciência dos seus conflitos e os conduzem até o fim. Desse ponto de vista, nenhuma singularidade nos diferencia, sequer o sentimento de desterro em nossa própria terra, que afinal de contas deve ser comum a boa parte das sociedades-fragmento que são produto da aventura européia no trópico. (Tomo o termo "sociedades-fragmento" do historiador Louis Hartz, o autor de The Liberal Tradition in America, que o usa para dar conta do processo pelo qual os países do Novo Mundo constróem suas próprias culturas a partir dos fragmentos da cultura européia dos quais se apropriam. É da mesma família das "idéias fora do lugar", metáfora cunhada por Roberto Schwarz para explorar processos e resultados da imigração das idéias no trópico).

Longe de mim, no entanto, negar que o caráter a um tempo exacerbado e rarefeito com que costumamos lidar com as relações entre as idéias e o mundo real, entre ser e dever-ser, marcou profundamente nossa vida intelectual. Ao contrário, reconheço que aqui reside um de seus veios mais instigantes. Extremada a diferença, topamos com a volubilidade do intelectual ou com a bizarria dos engajados, dos quais Brás Cubas e Policarpo Quaresma foram as mais completas expressões literárias; estilizada a relação, ela pode dar e deu na dicotomia entre país real e país legal, que percorre como um fio vermelho a reflexão brasileira, do Visconde de Uruguai a Cruz Costa, de Tavares Bastos a Bolívar Lamounier, de Guerreiro Ramos a Wanderley Guilherme dos Santos, de Hélio Jaguaribe a Fernando Henrique Cardoso; radicalizado o descompasso, tudo se passa como se o Brasil fosse, para o bem e para o mal, o "produto de uma teoria", como na esdrúxula observação de Euclides da Cunha; - todas percepções e modos de ver que acentuam o suposto "excepcionalismo" do país e servem de base tanto à apologética conservadora quando ao desencanto, liberal ou esquerdista, com o que seria o artificialismo congênito das instituições.

A expressão mais nítida desse divórcio entre ser e dever-ser e conseqüente sentimento liberal talvez seja a formulada por Raymundo Faoro no final da primeira edição de Os Donos do Poder (é verdade que em termos cujo radicalismo abstrato - expresso na disjuntiva entre o imperativo ético da mudança e descrença na sua possibilidade, da qual só deriva uma Grande Recusa ou o conformismo total - vem atenuado na edição de 1973): 
Parece impossível, como ensinou Jesus, deitar vinho novo em odres velhos, porque, em fermentando o vinho, aqueles se rompem e este se entorna. É necessário que o vinho novo seja conservado em odres novos, para que ambos se conservem.

As velhas caldeiras, a fim de que se expanda a pressão, hão de romper-se e fragmentar-se em mil peças disformes. A explosão há de ser total e profunda e velhos odres devem ser abandonados. Somente assim a criança tolhida e enferma terá ensejo de crescer e tornar-se adulta. Essas são as expectativas cegas da fé, que a razão e a análise histórica repelem.

Não há dúvida de que, variada a ênfase, estilos analíticos e opções ideológicas, é a mesma cesura entre o normativo e o empírico que torna plausível o modo como Oliveira Vianna organiza a sua narrativa, vendo o nosso desacerto como resultado da ação levada à cabo pelas idéias, ou seja, "pela idéia liberal, pela idéia abolicionista, pela idéia federativa, pela idéia republicana e pelas fermentações morais que determinaram as chamadas "questões militares", todas elas alérgicas ao "sentimento de nossas realidades" e vazias do "poder transfigurador da vontade" dos "reacionários audazes" que souberam entender o país e mantê-lo sob rédea curta. Faz sentido, mas é falso. Do mesmo modo, ela explica a frustração e o desespero dos engenheiros institucionais auto-investidos da missão de domar nossa selvagem democracia, pois a política brasileira realmente existente continua rebelde às tentativas de reduzi-la ao jogo schumpeteriano das instituições, ainda não é e dificilmente será mera "operação política", apática às disputas para fazer vencer visões-de-mundo.

\section{DILEMAS DA INTELIGÊNCIA}

Seja como for, parece claro que aquela constelação histórica e essa polarização ideológica entre idealismos orgânicos e constitucionais produzem e reproduzem o peculiar protagonismo dos intelectuais brasileiros. De fato, pensar o Brasil tem sido, desde o Império, uma missão ou um privilégio dos intelectuais. Haverá sempre alguém para dizer que essa é precisamente a marca da infelicidade do país e da soberba dos intelectuais - e terá razão. Não temos uma história feliz e os países que não as tem costumam delegar muito aos seus intelectuais. Ao contrário de nações como os Estados Unidos e a Inglaterra, onde a hegemonia sempre nasceu da fábrica e intelectualidade, política profissional e negócios parecem andar juntas, a nossa é uma dessas cuja inteligência 
sempre sofreu a tentação de se converter numa intelligentsia. Ora, desde a crítica conservadora à Revolução Francesa sabemos que a formação de grupo social desse tipo pressupõe talento sem propriedade, a existência de um conjunto de intelectuais marginalizados do mundo da produção e das instituições políticas costumeiras, situação só possível em grande escala em países cujas classes dominantes não conseguiram ou se recusaram a incorporar os seus subalternos aos mercados. Solta no ar, a intelectualidade sucumbe periodicamente ao fascínio de "ir ao povo" ou sente-se compelida a "dar voz aos que não têm voz". Ou, ao contrário e mais sistematicamente, considera-se investida de um mandato, cuja formulação exemplar devemos a Joaquim Nabuco: trata-se de uma "dupla delegação, inconsciente da parte dos que a fazem, mas, em ambos os casos, interpretada pelos que a aceitam como um mandato que se não pode renunciar". Ora, é essa "advocacia gratuita" das classes sociais que têm dificuldade em defender seus direitos e tomar consciência deles, que alimenta ou exprime a peculiar tradição de rebeldia do intelectual brasileiro, que vim tematizando até aqui.

Sei bem que tudo isso vem sendo transformado nos últimos tempos, quando pela primeira vez nosso tipo de capitalismo se tem demonstrado capaz de cooptar os mais capazes, fazer de todo economista um banqueiro em potencial, condenar os cientistas sociais ao papel de consultores do Estado e do mercado, induzir os pesquisadores à reprodução da "agenda americana de pesquisa" (a expressão é de Luiz Werneck Vianna), reduzir a política à administração das necessidades de grupos sociais segmentados e vender a idéia de que ação coletiva boa é apenas aquela via instituições e corporações acadêmicas e profissionais. Também aqui, foram os artistas que se anteciparam na percepção desse fenômeno de longa duração. Cito Paulo Pontes e Chico Buarque de Holanda, na apresentação a Gota D'Água:

Hoje é possível perceber que essa rebeldia era fruto da incapacidade que os diversos projetos colonizadores sempre tiveram em assimilar amplos setores das camadas médias e dar-lhes uma função dinâmica no processo social. O que estava reservado ao intelectual pequeno burguês antes do período a que estamos nos referindo? $\mathrm{O}$ jornalismo mal pago, o funcionalismo público, uma cadeira de professor de liceu, o botequim, a utopia, a rebeldia. Por falta de função ele era posto à margem. Até muito pouco tempo eram muito poucas as opções do estudante universitário - tudo era criado fora, $\mathrm{o}$ carro, a geladeira e a ideologia. Assim, o sistema econômico não tinha como assimilar a capacidade criadora dos melhores quadros da pequena burguesia que ficavam colocados, perigosamente, no 
limite da rebeldia. O que acontece agora, inversamente, é que a radical experiência capitalista que se faz aqui começa a dar sentido produtivo à atividade dos setores intelectualizados da pequena burguesia: na tecnocracia, no planejamento, nos meios de comunicação, na propaganda, nas carreiras técnicas qualificadas, na vida acadêmica orientada num sentido cada vez mais pragmático, etc. $\mathrm{O}$ disco, o livro, o filme, a dramaturgia, começam a ser produtos industriais. $\mathrm{O}$ sistema não coopta todos porque o capitalismo é, por natureza, seletivo. Mas atrai os mais capazes.

\section{PENSAR A REVOLUÇÃO CAPITALISTA}

Ora, é nesse novo contexto - esse é o meu terceiro ponto - que estamos sendo instigados a repensar o Brasil ou ser devorados. De fato, ainda não ousamos chamar o que está ocorrendo no país pelo seu nome - uma revolução capitalista; mas é disso que se trata e é essa a determinação mais global com que temos de lidar para pensá-lo. Devemos entender por ela não apenas as reformas institucionais que a aliança governamental atual tem implementado, mas a magnitude das mudanças que vêm acontecendo na forma do Estado, em suas relações com as classes sociais, na estrutura patrimonial e no modo de operação dos grupos dominantes, no estilo das políticas públicas, na diluição da capacidade de intervenção organizada dos grupos subalternos, nas formas de consciência social, etc. Devemos entender sobretudo a naturalização do individualismo possessivo, que pela primeira vez em nossa história enraizou-se de alto a baixo e, em que pese o sentimento anti-capitalista notavelmente resistente em muitas camadas populares, tornou-se capaz de inspirar a conduta e dirigir a vida cotidiana de grandes grupos sociais; bem como a criação das bases materiais e políticas que separaram a intelectualidade de classe média das classes subalternas tradicionalmente aliadas e permitiram essa fusão entre o mundo industrial e financeiro e a grande intelectualidade.

Para não ser mal-entendido, vale abrir um parênteses e ressaltar o caráter ambivalente, de fato contraditório, desse processo, que ao reorganizar as bases do capitalismo brasileiro até então existente está varrendo de cena comportamentos e valores tradicionais, convive, dentro de certos limites, com os mais variados arranjos governamentais e ganhou velocidade e corpo apenas em democracia, aliás, a mais ampla que o país conheceu.

$\mathrm{Na}$ impossibilidade de aprofundar aqui esses argumentos, limitome a assinalar sumariamente alguns de seus efeitos no modo pelo qual se vem 
analisando o Brasil. O primeiro é uma das conseqüências mais complicadas da transformação do intelectual em especialista, das ciências sociais em técnicas de racionalização das demandas sociais, do trabalho acadêmico em reprodução dos interesses e programas das agências estatais e financeiras. É que, por maior que seja sua dimensão democratizante comparada com o antigo mandarinato, a tecnificação da atividade intelectual e a fragmentação da pesquisa científica numa miríade de disciplinas e subdisciplinas fechadas e especializadas no exame de limitados objetos, acabam por bloquear a possibilidade de pensar o conjunto, reduzem a reflexão à expressão reificada do próprio processo social.

\section{LIMITES DA ÓTICA INSTITUCIONAL}

Nessa circunstância, a generalização de um certo tipo de institucionalismo não é somente uma escolha racional mas uma inevitabilidade histórica. Não tenho nenhuma dúvida quanto à relevância do estudo das instituições, sobretudo em democracia, e à necessidade de responder ao desafio institucionalista. Mas talvez valha a pena chamar a atenção para o fato de como o horizontalismo de suas análises prolonga e renova um estilo de pensamento arraigado na vida política brasileira desde o Império, para o qual basta o bom funcionamento das instituições para termos democracia, basta a boa lei para produzir a boa sociedade. E, se sua legitimidade deriva da própria experiência democrática em curso, freqüentemente é difícil perceber onde termina o seu realismo e começa a aceitação resignada (e a apologia indireta) do existente, como a ênfase no avanço possível serve de freio ao necessário, quando o reconhecimento do gradualismo do processo se transforma em capitulação diante do dado, — que é, me parece, ao que leva a aceitação do transformismo não (exclusivamente) como "critério de interpretação", mas como norma reguladora da ação.

Ora, quebrado o fetiche desses "idealismos" opostos e complementares, e dissolvendo-se, como vem acontecendo, a ilusão de que a época seria a da realização do "fim da história", que independentemente de suas instituições e trajetória cada país estaria condenado à se dissolver no Mesmo, não exigiria a experiência brasileira outro tipo de abordagem? Em um mundo em que os conflitos radicais não foram eliminados e o fenômeno ideológico teima em não morrer, deve uma situação na qual as grandes interpretações do país continuam a ser chave na formação da vontade e na direção política dos grandes grupos sociais, ser descrita como atraso, resíduo, ou como antecipação em relação à evolução mundial? 
Não pretendo terminar com nenhuma nota utópica. Sei bem que uma concepção unitária e realista do mundo - que está subjacente, afinal, à essa proposta de pensar o Brasil — já não conta sequer com aquela garantia metodológica que um dia se considerou própria da dialética, como método de análise enfim adequado às estruturas do capitalismo; como pensamento que, fora de moda nas ciências naturais, encontrava nas ciências humanas o seu ambiente natural; como teoria cujos conceitos e estrutura categorial reproduziriam flexivelmente o andamento da própria existência. Dilapidada a sobrevida que havia adquirido uma vez passado o momento de sua realização, perdida a carga de universalidade que um dia ambicionou, ela parece reduzida a mero ponto de vista, pesado e anacrônico, tanto mais que a própria evolução do capitalismo e o irremediável esgotamento do que se pretendia transformação do mundo, parecem tornar obsoletas a constelação histórica e a ambição teórica que lhes permitiram nascer.

Mas a exigência a que satisfazia não continua, apesar de tudo, de pé? Em que lugar encontrar-se-ia outra orientação com coragem de pensar arrebatadoramente, inclusive contra si própria, em meio ao "esterco das contradições"? Em seus melhores dias, essa perspectiva constituía, como já disse Giannotti ao examinar as origens da dialética do trabalho, "um precioso recurso contra a redução positivista do fato humano à coisa ou ao comportamento fragmentado". Por mais fora de moda que esteja, ela conserva sobre a ciência (política, social) convencional a vantagem, filha do ceticismo, de jamais esquecer que o que os atores dizem não corresponde simplesmente ao que fazem, que as escolhas dos agentes não resumem o sentido global do processo e, sobretudo, que tudo que existe merece perecer. Tudo isso condicionado pela distinta maneira de abordar o dado. Como disse certeiramente o último Goldmann, ao tratar da criação cultural na sociedade moderna:

O grande valor da dialética é precisamente o de não julgar moralmente e não dizer apenas: queremos a democracia, é necessário introduzi-la; queremos a revolução, é necessário fazê-la - mas perguntar-se quais as forças reais de transformação, qual a maneira de achar na realidade, no objeto, na sociedade, o sujeito da transformação, para tentar falar na sua perspectiva e assegurar, sabendo perfeitamente quais são os riscos do malogro, o caminho para....

Salvo engano, é dessa maneira que carece pensar o Brasil e é esta identidade de esquerda que merece ser reafirmada. 


\section{O PENSAR E O AGIR}

\section{LUIZ JORGE WERNECK VIANNA}

Agradeço o convite e desejo uma longa vida ao CEDEC! Desconfio que tenha sido, se não membro fundador, um de seus primeiros colaboradores - deve haver algum papel em que isso esteja registrado. Mas, existindo ou não a prova do que alego, o que importa é saudar o que se comemora hoje. O tema é Pensar o Brasil, e diante dele me sinto em situação semelhante a do meu tempo de colégio primário, quando as professoras nos exibiam gravuras - em geral, cenas bucólicas da vida rural -, exigindo de nós uma composição. Diante da gravura, estávamos obrigados a ter idéias e criar uma fabulação, tal como me sinto agora, e lembro que naqueles momentos sempre procurava me apressar para ganhar rápido o direito ao recreio e à merenda, exatamente como farei nesse instante, inclusive porque hoje é dia de festa, que, aliás, já nos espera ali fora.

Pensar o Brasil é muito complicado. Somos o quê? Somos o filho do latifúndio com a escravidão, do jacaré com a cobra d'água, um resultado dessa construção. Ainda provocando: somos o príncipe encantado nascido desse cruzamento bizarro, que, tudo pesado, deu certo. Afinal, estamos aqui, cuidando de pensar o Brasil, enquanto ele está se fazendo lá fora, não é verdade? E sempre tivemos a consciência de que esse país tinha uma vocação expansiva, não necessariamente reconhecida no plano dos que o pensam, porque o Brasil pensa com os pés, como nos grandes movimentos migratórios que vararam e ainda varam esse continente, esse contingente imenso de 170 milhões de brasileiros que criou uma realidade fantástica, um país que é uma novidade e uma singularidade!

Adoto, nessa hora em que tantos da intelligentsia negam a vitalidade da experiência civilizatória brasileira, o tom provocativo da linguagem de ecos messiânicos, e me ponho em linha de continuidade com a tradição que vem de Gilberto Freyre a Darcy Ribeiro, que jamais perdeu de vista o que havia em nós de Rússia e de América - Gilberto, como se sabe, em Casa Grande e Senzala chegou a nos designar como a Rússia americana. Não 
somos, é claro, filhos do pensamento, como tantos dizem da Alemanha de inícios do século XVIII, e não se pode entender o Brasil sem a dimensão do agir, embora de um agir muito fragmentado, difuso e disperso, como o que se faz presente nas narrativas da conquista do Oeste, de Sérgio Buarque de Holanda. Também "andando", freqüentemente apenas "andando", fizemos o Brasil.

\section{O IMPÉRIO E AS ELITES DO PENSAR}

Penso que esse tema faz mais sentido hoje do que em qualquer outro momento anterior, e foi sob essa intuição que pretendi armar um caminho de aproximação à questão que nos é proposta pelo CEDEC. Para tanto, voltei a Nabuco, um Nabuco de que sempre me utilizo nesta seguinte passagem de Minha Formação: "Há duas espécies de movimento em política, um de que fazemos parte supondo estar parados, como o movimento da Terra, que não sentimos, outro o movimento que parte de nós mesmos. Na política são poucos os que têm consciência do primeiro, no entanto, esse é talvez o único que não é pura agitação". Dessa citação extraio o registro clássico entre as elites do pensar em contraposição ao agir, o pensar como uma atividade de eleitos, daqueles que detêm o sentido da civilização e que são capazes de calcular o mundo provisório, o mundo precário, um mundo que não tem sustentação interna, condenado a soçobrar se for entregue a si mesmo.

Que mundo é esse que não tem sustentação? É o da insolidariedade social, o do latifúndio, o da fragmentação, o do clã, o mundo da parentela, em que o plano do interesse não tem como se elevar ao do pensamento. Sobre isso versam as páginas clássicas de Maria Silvia de Carvalho Franco, referentes à atividade econômica do café e a como, a partir dela, não se chega ao plano abstrato do Estado nem a um projeto comum - não se atinge a região do pensamento. $\mathrm{O}$ fazendeiro, é frase dela, foi sobretudo um solitário. O interesse entre nós nasce com essa marca, a marca da solidão, da desintegração, cedendo à força simplificadora do latifúndio. Embora em sua bela análise Maria Sílvia não mobilize Populações meridionais do Brasil, de Oliveira Vianna, em ambos se reconhece a presença de um certo Nabuco, que não reconhecia no agir uma instância de fundação para o pensamento.

Pensar, portanto, na hora inaugural em que se forma o Estadonação, é uma atividade que não tem como partir do agir, é uma atividade de eleitos, dos que detêm em si as luzes da razão e o caminho do futuro, daqueles que, tendo o pé no outro lado do Atlântico, têm a premonição de para onde devemos ir, trabalhando "nessas vastas solidões", procurando evitar esses 
"pequenos movimentos" que não levam a nada, porque são pura agitação. Entender "o movimento da Terra"... Qual movimento da Terra? A escravidão é iníqua, mas é necessária; o latifúndio é anacrônico, mas não há estrutura econômica a pôr no seu lugar... O pensar, nesse sentido, deve, inclusive, interditar certas formas do agir, que não terão credenciais para se elevar ao plano do pensamento, como na ação plebéia dos homens com inscrição intersticial no mundo - os tropeiros, os vendeiros, os sitiantes, seres que vivem na dimensão da necessidade. Tais agentes podem, talvez, alcançar uma certa mobilidade social, mas, submersos no sistema existente, encontram-se limitados pela rusticidade dos seus interesses, não chegam ao pensamento, não formam identidades. Não representam nem encarnam um padrão civilizatório; expressam uma materialidade sem idealidade, que somente o tempo longo, daquele tipo que não sentimos transcorrer, poderia educar para a vida civil.

Dizia Nabuco que "pertencemos à América pelo sentimento novo, flutuante do nosso espírito, e à Europa por suas camadas estratificadas. O que é leve, o que é ligeiro, o que flutua, é o sentimento novo. O que tem lastro, o que efetivamente tem uma raiz, que deve e pode prosperar, está nas suas camadas estratificadas".

Estaríamos assim condenados, concluía ele, sob os efeitos dessa tensão, à mais terrível das instabilidades, uma vez que não haveria possibilidade de comunicação entre as elites e a massa do povo, dificultando, ou mesmo obstando, ao menos por ora, a via inglesa da incorporação deste último aos valores das primeiras. Estaríamos, aqui, em um trecho do planeta do qual a humanidade ainda não teria tomado posse, uma espécie de jardim infantil. A vasta solidão do Brasil seria, na verdade, um efeito desse lugar ainda imaturo para as aventuras do espírito. O sedimento flutuante novo estaria presente na paixão mercantil, no homem de negócios, no Brasil que se faz com os pés. E prossegue: "não quero dizer que haja duas humanidades, a alta e a baixa, e que nós sejamos desta última". Talvez a humanidade, concluía Nabuco, "se renove um dia pelos seus galhos americanos, mas no século em que vivemos, o espírito humano está do outro lado do Atlântico. O Novo Mundo, para tudo que tem imaginação estética ou histórica, é uma verdadeira solidão".

Esse é o Nabuco ou esse é o Império? O Império pensou assim, assim selou o afastamento entre o plano do pensar e o plano do agir. O pensar não só está separado, mas desajustado, desconfiado da empiria brasileira, especialmente do mundo mercantil. Dir-se-á: "você está invocando os vendeiros, os tropeiros" - mas se eu invocar Mauá, Tavares Bastos, Rebouças - e lembro, aqui, do brilhante O Quinto Século, de Maria Alice Rezende de Carvalho - , homens dos grandes interesses americanos moder- 
nos, que nasceram e se fortaleceram no Império e que não conseguiram se alçar ao plano da atividade pública, ao plano abstrato do Estado, ao plano do pensamento e de um pensamento organizador? Qual era a condição para que pensamento e ação pudessem convergir?

Oliveira Vianna, em 1918, em Populações Meridionais..., entendeu isso melhor do que ninguém. A possibilidade do pensar e do agir convergirem estava na questão agrária, na possibilidade dos intelectuais do liberalismo democrático e dos matutos do Centro-Sul se encontrarem em torno de uma reforma agrária radical, idéia que lhe parecia extraordinariamente ameaçadora, porque traria consigo a revolução democrática, e com ela uma fragmentação política em escala mais grave que a do período da Regência, importando o abandono e a perda da grande obra do pensamento do Império, que teria sido a de constituir a unidade nacional. Para ele a unidade nacional ou seria fruto do pensar ou não teria como se realizar, resultado que foi do papel criativo de uma paixão, da vocação de uma elite territorialista, ibérica, não tendo como encontrar os seus fundamentos na ação de homens apenas treinados em uma vida mercantil incipiente. A comparação em Oliveira Vianna é recorrente: não nascemos como a federação norte-americana, unificada por baixo, pela integração econômica, que, entre nós, mal estaria no horizonte.

Somos uma federação porque fomos uma unidade construída no plano do pensamento e imposta pela política — o Brasil seria congenitamente metafísico. Enquanto que a busca da federação, como no Tavares Bastos de $A$ Província, apontaria para o caminho do agir, com todos os riscos da fragmentação admitidos pelo publicista do Império, nós somente somos a unidade porque aqui presidiu o caminho do pensar. São realidades inamovíveis! Não temos como deslocar as marcas do latifúndio que estão na raiz da nossa formação, base da nacionalidade, dizia Oliveira Vianna. Não vamos deslocar as marcas da escravidão que sedimentaram a nossa específica sensibilidade e o mundo dos nossos sentimentos, como interpretaram o Nabuco de Massangana e o Gilberto Freyre de Casa Grande e Senzala. O Brasil não suporta rupturas, sob pena de desintegração, porque a matriz do interesse não lhe concede sustentação. Caetano Veloso, em "Noites do Norte", uma belíssima composição, não à toa celebra Nabuco musicando a sua prosa, celebrando a sensibilidade da população submetida à escravidão como uma marca permanente do Brasil.

O pensar e o agir, portanto, nascem entre nós com essa antinomia. E mais: apostar no agir era, por exemplo, apostar na Regência, cuja inclinação pela livre iniciativa individual e pela descentralização nos teria aproximado da secessão. A cena de fabulação dos estadistas do Império, recriadores em solo americano do territorialismo ibérico, como na bela 
demonstração de Rubem Barbosa Filho em Tradição e Artifício, à base da experiência dos movimentos autonomistas da Regência, era o de que a primazia do agir levaria à balcanização do país. Sem dúvida, para eles, o preço da unidade era o da restrição à liberdade. Outra marca inamovível - a federação como obra do Centro político.

\section{A MODULAÇÃO REPUBLICANA}

A República introduz uma modulação nessa relação entre o pensar e o agir. Em primeiro lugar, porque a República promove o interesse, cuja matriz se encontra em São Paulo -- a República paulista. Está aqui o Renato Lessa com o seu importante A Invenção Republicana, e, para encurtar razões, penso que a República é, tal como a Independência, mais uma revolução encapuzada, como há tempos sustentou Regis Andrade em tese de doutorado, infelizmente ainda inédita. Enfatizar o tema dos "bestializados" no evento da proclamação da República a fim de destacar a recepção passiva da população a ele, se contém, é claro, a sua verdade, pode conduzir ao ocultamento do que o pacto republicano importou em termos de mudanças político-sociais desencadeadas a partir dele. Mudanças que foram sentidas, no seu alcance maior, na passagem dos anos 10 para os anos 20 , com as greves de 17 , as greves de 18 e 19 , sobretudo com a rebelião tenentista de 22 , mais tarde radicalizada sob a forma de um movimento permanente com a Coluna Prestes, naquela extraordinária coincidência que levou a que, nesse mesmo ano, fosse formado o Partido Comunista Brasileiro e organizada a Semana de Arte Moderna.

Data daí a tentativa de apropriação por parte da matriz do interesse e do agir do que poderia elevá-la ao plano do pensamento. Qual é o movimento que domina a intelligentzia da época? A ida ao Brasil! Os sanitaristas, Oswaldo Cruz, os sertanistas, Rondon, os artistas, Mário de Andrade, Villalobos, a literatura regional, os tenentes... Descortinar o lugar de onde se pudesse extrair uma estética, uma imaginação, um pensamento singular. A Coluna Prestes vagueia pelo Brasil sem pensamento, como uma mula sem cabeça, passando pelo latifúndio sem ter uma palavra de ordem de revolução agrária - ver, por exemplo, o excelente relato da Coluna realizado por Anita Leocádia Prestes. Em todos, o que se tem é um sentimento que ainda não consegue se formalizar em idéia, na expectativa de que a exposição à matériaprima do Brasil em estado bruto produza o fiat que leve ao conhecimento, ao pensar. Intelligentzia posta em movimento, a mobilidade social que alarga $\mathrm{o}$ espaço da razão brasileira, olhando, escrutinando, selecionando temas para a 
saga a ser ainda construída, como no caso do Mário, de Villa, da Coluna. Ida ao Brasil, ida ao povo - não se trata mais do agir mercantil, mas de um agir orientado para a reflexão e para a produção de um pensamento.

Essa promissora década é bloqueada, como se sabe, pela Revolução de 30, que dá partida a uma intervenção modernizadora e autoritária sobre a sociedade, com elementos de garantia de direitos, de elevação das camadas populares, muito especialmente dos trabalhadores urbanos, mas que, em contrapartida, lhes suprime a autonomia de suas associações e restringe, em geral, as liberdades civis e públicas de todo o corpo social. Pensar e agir, no contexto da institucionalidade corporativa imposta a partir da década de 30, vai importar uma racionalização dos interesses, realizada pela mediação dos intérpretes políticos do Estado-nação, no sentido de que eles se orientem para fins de natureza pública, tal como entendidos por aqueles intérpretes, detentores da representação da razão. O interesse e o agir estão legitimados, desde que subsumidos a um pensamento que os organize por cima. Exemplar disso é o artigo 135 da Carta de 1937, a "Polaca", ao prescrever que "na iniciativa individual, no poder de creação, de organização e de invenção do indivíduo, exercido nos limites do bem público, funda-se a riqueza e a prosperidade nacional. A intervenção do Estado no domínio econômico só se legitima para suprir as deficiências da iniciativa individual e coordenar os fatores da produção, de maneira a evitar ou resolver os seus conflitos e introduzir no jogo das competições individuais o pensamento dos interesses da Nação, representado pelo Estado" (grifos do autor). Sobre o interesse, um árbitro racional. E se ele é base material para o pensar, não será, contudo, a partir dele, e nem dos personagens que o portam, que o pensamento deve realizar a sua trajetória brasileira.

\section{UMA FELIZ CONVERGÊNCIA...}

Findo o Estado Novo, um novo capítulo na relação entre o pensar e o agir, o período entre 1945 e 1964, momento em que, de verdade, o agir pretende se constituir em pensamento. Vou ler um trecho que sempre cito em minhas análises sobre a política moderna brasileira, extraído da Declaração de Março de 1958 do Partido Comunista Brasileiro: "O caminho pacífico da revolução brasileira é possível em virtude de fatores como a democratização crescente da vida política, o ascenso do movimento operário e o desenvolvimento da frente única nacionalista em nosso país. O povo brasileiro pode resolver pacificamente os seus problemas básicos com a acumulação gradual 
mas incessante de reformas profundas e conseqüentes, na estrutura econômica e nas instituições políticas, chegando-se até à realização completa das transformações radicais colocadas na ordem do dia pelo próprio desenvolvimento econômico/social da nação".

$\mathrm{Na}$ aparência, uma volta a Nabuco, certamente que não ao Nabuco do pensar refratário ao agir, e que o nega a fim de que o pensamento se manifeste na sua pureza. Para ele, a civilização nos chegaria como obra do tempo, processo gradual e molecular, como os que nos chegam, silenciosos e quase imperceptíveis, do movimento da Terra, enquanto seus valores e ideais, ainda não generalizáveis, seriam cultivados pelas elites dos homens públicos, toda uma modelagem vazada em termos de uma necessária oposição entre os planos do ideal e os do real. A volta a Nabuco é apenas aparente na medida em que a Declaração de 1958 afirma uma relação de feliz convergência entre eles: a democratização crescente da vida política, o ascenso do movimento operário e o desenvolvimento da frente única nacionalista no país indicariam, no cerne do processo em curso, algo de intrinsecamente progressista, de democrático, significando a presença de um elemento transformístico, de caráter positivo, isto é, atuando a favor das forças da mudança social, como se inscrito no próprio "movimento da Terra". Assim, se esse era o resultado que o pensamento produzia sobre o estado de coisas efetivamente existente no país, agir significava dirigir o movimento da Terra, que se evidenciava depois de desvendado por meio de uma operação intelectual.

Afinal, tinha-se descoberto, a contrapelo de Nabuco, uma relação de homologia entre pensar e agir, em que cada termo servia ao outro. E a afirmação clássica, que deve ser de 1961, de um dos grandes membros da intelligentzia da época, Álvaro Vieira Pinto, parodiando Lenin, que sem teoria do desenvolvimento não há desenvolvimento, pretendia significar a possibilidade de uma aproximação feliz entre o pensar e o agir, abrindo para a Nação, consciente da sua circunstância, o caminho para a construção da sua identidade. (Vale notar que, tendo mobilizado o Vieira Pinto, em Consciência e realidade nacional, de óbvia inspiração em Heidegger, ocorreu-me que, coincidentemente ou não, o filósofo alemão, em Que significa pensar?, se faz as mesmas perguntas que servem à organização dessa conferência. A propósito, sobre a obra magna de Vieira Pinto vale citar, por seu interesse, a recente tese de doutoramento, defendida no IUPERJ, de Norma Côrtes).

Era possível, pois, no período compreendido entre os anos de 45 e 64, conceber o interesse, particularmente o das grandes maiorias, como base de assentamento para a composição da idéia de Nação e para uma reforma democrático-popular do Estado. Um pensar que não toma distância do 
agir a fim de evitar a perda do seu mandato civilizatório, e nem o aceita apenas como matéria-prima administrada para os propósitos da modernização econômica, mas que é concebido a partir do interesse das grandes maiorias e da sua elevação em propósitos ético-morais.

\section{... E UMA INFAUSTA SEPARAÇÃO}

Isso é o que se perde com o golpe de 1964, que se, de um lado, vai importar na valorização do agir na esfera isolada da economia, um agir, portanto, puramente instrumental, cujos símbolos são a mobilização dos setores subalternos mais pobres do campo para o garimpo de Serra Pelada e para a colonização da Transamazônica, de outro, vai reduzir, pela violência política, a sociedade à imobilidade, mantendo-a em estado de infantilização cívica. Vivemos hoje sob a influência direta disso, de um intenso processo de modernização econômica que separou o agir do pensar, o público do privado, e que produziu o efeito de, no lugar de cidadãos, termos máquinas desejantes, os interesses mal compreendidos proclamados como virtudes necessárias a uma boa adaptação ao mundo do mercado, traços nefastos que sobreviveram à ditadura e que não serão fáceis de deslocar, em particular quando se considera que os novos seres da modernidade brasileira começam a sua história sem a memória, com freqüência porque a rejeitam liminarmente, das lutas e das construções intelectuais do passado.

Às ciências sociais brasileiras coube, por razões que não importam considerar aqui, o papel da produção de uma narrativa e de uma interpretação do país, servindo à sociedade com diagnósticos sobre a natureza do estado de coisas existentes, especialmente à época da ditadura militar. Os recentes avanços na institucionalização do trabalho científico não têm implicado, como muitos supunham, a perda desse veio, que, ao contrário, tem encontrado um número, cada vez maior, de praticantes entre os cientistas sociais. Decerto que dos intelectuais de hoje não se espera a pretensão de se fazerem substitutivos dos partidos políticos e dos movimentos sociais, mas deles se pode legitimamente esperar que honrem as tradições da USP e do ISEB dos anos 50 e 60, que sempre foram as de conceber um destino de afirmação para os brasileiros e aproximar a intelligentzia do seu povo. Os 25 anos do CEDEC nos pedem um compromisso como cientistas sociais, que interpreto no sentido de que devemos animar a saga dos brasileiros em continuar tentando construir uma sociedade livre, justa e fraterna, defendendo a sua história e seus valores dos que querem nos condenar a uma forma de pensar - a do pensamento único, que certamente não tem levado em conta a nossa forma de agir. 